\title{
Immigration and Unemployment of Skilled and Unskilled Labor
}

\author{
Shigemi Yabuuchi \\ Nagoya City University
}

\begin{abstract}
This paper discusses the problem of unemployment in developed countries that faces international labor movement. There are two types of unemployment. The first traditional type of unemployment exists simply because the common wage rate is fixed and higher than the equilibrium level. The second one may exist when the wage rate in one sector is high and fixed, while that in the other is flexible. On the other hand, an extensive movement of labor among countries has been observed. Thus, this paper investigates the effects of immigration and other policies on the two types of unemployment.
\end{abstract}

- JEL classification: F16, F22, J64, R23

- Keywords: Unemployment, Skilled labor, Unskilled labor, Immigration

\section{Introduction}

Unemployment of both elderly skilled labor and younger unskilled labor is found in certain developed countries. Unemployment of elderly skilled labor is characterized as being traditional because it occurs as a result of the high and nonflexible wage rate. This type of employment can be observed particularly among middle-aged and elderly workers. On the other hand, a remarkable increase has been observed in the unemployment of younger unskilled workers. This type of unemployment is characterized as being voluntary because these workers have

\footnotetext{
*Corresponding address: Shigemi Yabuuchi, Department of Economics, Nagoya City University, Yamanohata, Mizuho Nagoya 467-8501 Japan, Tel\&Fax: +81-52-872-5739, E-mail: yabuuchi@ econ.nagoya-cu.ac.jp 
excessive expectations from their jobs and rely on others for a living. In other words, if they wish, it is possible for younger workers to be employed in certain suitable industries. However, they prefer voluntary unemployment in the hope of securing their ideal job someday. Recently, a tendency has been observed among younger workers wherein they insist on finding jobs only in the industry that they prefer. This situation is highly similar to that witnessed in developing countries. In these countries, rural workers are attracted to the "bright lights of the city" and migrate to urban areas at the risk of unemployment, even though they can be fully employed in rural areas at the prevailing rural wage rate. Harris and Todaro (1970) developed this labor allocation mechanism between the rural and urban areas in developing countries. Thus, the problem of unemployment of the younger generation in the economy with international factor movements can be analyzed by employing Harris and Todaro's approach. Various aspects of the Harris-Todaro (HT hereafter) model have been discussed by several trade theorists such as Bhagwati and Srinivasan (1974), Corden and Findlay (1975), Khan (1980), Batra and Naqvi (1987), Beladi and Naqvi (1988), Hazari and Sgro (1991), Marjit (1991), Neary (1981), Gupta (1993), Yabuuchi (1993), Chao and Yu (1992, 1996), Basu (2000), Yu and Jin (2002), Chaudhuri (2003), Gu and Yabuuchi (2003), and Marjit and Beladi (2003).

Our analysis is an extension of the mobile capital HT model that was developed by Corden and Findlay (1975) and followed by Batra and Naqvi (1987) and Yabuuchi $(1998,2007)$, among others. Yabuuchi (2007) introduced the difference between skilled and unskilled labor into the standard mobile capital HT model and analyzed the relationship between unemployment and the international movement of labor and capital. His analysis deals with unemployment problem of developing countries, and then concentrates on the unemployment of only unskilled labor in the traditional two-sector framework. In this paper, however, we introduce a third sector that is characterized as the absorption sector of unskilled daydreamers, and examine the problem of unemployment of both elderly skilled labor as well as younger unskilled labor in the model with three sectors and three factors. We will focus particularly on the interaction between domestic and international labor movements by paying special attention to the coexistence of 'disguised' unemployment in the form of part-time worker and two types of unemployment.

Both these types of unemployment have characteristic features. The unemployment of elderly workers causes personal hardships, social costs resulting from an inefficient allocation of labor, social instability, and so on. This type of 
unemployment is mostly involuntary because it is caused due to institutional and structural reasons. Thus, the primary concern of policy makers should be to alleviate unemployment involving both the unemployed workers themselves and the economy as a whole. The unemployment of younger unskilled workers involves an aspect of voluntary unemployment in the sense that these workers can be employed in another sector where the wage rate is low and the job is uninteresting. Therefore, at first sight, it appears that for the workers themselves, unemployment is not a serious problem; it is merely a matter of preference with regard to whether or not they would like to be employed in a suitable job of their choice. However, if this unemployment continues for a long period of time, it might result in social instability or loss of opportunity to accumulate technical knowledge in the most appropriate period. This type of unemployment is sometimes known as NEET (Not in Employment, Education, or Training). Thus, younger workers tend to remain unemployed and unskilled. Therefore, in this respect, the problem of unemployment is an extremely important concern for the country at large as well as for the unemployed workers themselves. Subsequently, we consider the effective policies that aim to reduce both this type of unemployment as well as the unemployment of elderly skilled labor.

The remainder of this paper is organized as follows. Section 2 presents the model and basic assumptions. Sections 3, 4, and 5 examine the effects of the international labor movement, production subsidies, and the wage policy on unemployment, respectively. Concluding remarks are provided in section 6 .

\section{The Model and Assumptions}

Let us consider a small open economy that has three sectors. Each sector produces $\operatorname{good} j, X_{j}(j=1,2,3)$. We assume that the unskilled workers find sector 2 to be attractive in terms of employment but they do not regard sector 1 in the same light. For simplicity, we label sectors 1 and 2 as the traditional and advanced manufacturing sectors, respectively. Sector 3 is a labor-absorbing sector that comprises industries such as light manufacturing, retailing, and food service, all of which employ numerous part-time workers. This third sector is similar to the informal sectors found in developing countries. The production of goods 1 and 2 require unskilled labor $\left(L_{j}\right)$, skilled labor $\left(H_{j}\right)$, and capital $\left(K_{j}\right)$, while the production of good 3 requires unskilled labor $\left(L_{3}\right)$ and capital $\left(K_{3}\right)$. Sector 3 does not employ skilled labor. This is a natural occurrence in light of the nature of this sector. 
Capital is also assumed to be specific to each sector. Thus, the production functions are as follows:

and

$$
K_{j}=F^{j}\left(L_{j}, H_{j}, K_{j}\right), \quad j=1,2
$$

$$
X_{3}=F^{3}\left(L_{3}, K_{3}\right)
$$

It is assumed that has positive and diminishing marginal products and is homogeneous of degree one. We also assume that unskilled and skilled labor mainly comprise younger and older generations, respectively.

Under perfect competition, we have

$$
\begin{gathered}
w_{1}=p_{1} F_{L}^{1}\left(L_{1}, H_{1}, K_{1}\right), \\
\overline{w_{2}}=p_{2} F_{L}^{2}\left(L_{2}, H_{2}, K_{2}\right), \\
w_{3}=p_{3} F_{L}^{3}\left(L_{3}, T\right), \\
s=p_{1} F_{H}^{1}\left(L_{1}, H_{1}, K_{1}\right)=p_{2} F_{H}^{2}\left(L_{2}, H_{2}, K_{2}\right),
\end{gathered}
$$

where $F_{k}^{j}$ is the marginal product of the $k$ th factor in the $j$ th sector $(k=L, H ; j=$ $1,2,3), w_{j}$ is the wage rate of unskilled labor in the jth sector, $s$ is the wage rate of skilled labor, and $p_{j}$ is the price of the $j$ th $\operatorname{good}(j=1,2,3)$. We assume that all goods are tradable and their prices are given exogenously. If sector 3 is a service industry, it is likely that it is a non-traded industry. In this case, the price must be determined endogenously. In this paper, although we assume that the price of good 3 is constant, this assumption constitutes an important extension that requires further examination.

The unemployment of elderly skilled labor has been observed in certain developed countries. This type of unemployment is characterized as being traditional because it occurs as a result of the high and nonflexible wage rate. This can be observed particularly among middle-aged and elderly workers. Thus, the wage rate of skilled labor is assumed to be constant. This is partly because firms have specific wage standards depending on the ages and industries to which the workers belong.

In the standard HT model, it is assumed that the wage rate in (manufacturing) 
sector $2\left(w_{2}\right)$ is set at a relatively high level, and it is rigid due to some political and/or institutional factors. However, the wage rate in (agricultural) sector $1\left(w_{1}\right)$ is flexible. In this situation, rural workers have two alternatives - they can either stay in rural areas and acquire jobs at low wage rates or migrate to urban areas at the risk of unemployment in search of a high wage income. Thus, the labor allocation mechanism between the sectors is shown as follows:

$$
w_{1}=w_{2} L_{2} /\left(L_{2}+L_{u}\right) \text { or } w_{1}(1+\lambda)=w_{2}
$$

where $L_{2}$ and $L_{u}$ represent employed and unemployed labor in the urban area, respectively, and $\lambda=L_{l} / L_{2}$. In the labor market equilibrium, therefore, the wage rate in sector $1\left(w_{1}\right)$ equals the expected wage income in sector 2 , which in turn equals the manufacturing wage rate $\left(w_{2}\right)$ multiplied by the probability of finding a job in the urban manufacturing sector $\left(L_{2} /\left(L_{2}+L_{u}\right)\right)$.

We apply this labor allocation mechanism to the job search behavior of unskilled labor in developed countries. Thus, unskilled labor can obtain secure (but uninteresting) jobs in the unattractive sector (for example, the traditional manufacturing sector) at low wage rates; alternatively, they can seek high wages and/or attractive jobs at the risk of unemployment or disguised unemployment (as a part-time worker) in, for example, a labor-using service industry. Unskilled labor prefer to be unemployed or employed as temporary workers until they acquire their ideal job by being in the vicinity of the attractive sector. This appears to be reflective of the behavior of several younger unskilled job-seekers in developed countries. We refer to the "area" that includes the attractive sector, the laborabsorbing sector, and the unemployment pool as the advanced area. This area is a conceptual one. However, this does not necessarily imply that the labor-absorbing sector and the unemployment pool are geographically located near the attractive sector. The area consisting of the unattractive sector is termed as the traditional area.

Based on the HT model, we assume that the advanced-sector wage rate is fixed at a higher level than the traditional-sector wage rate. This is because firms in the advanced sector have well-organized trade unions and/or certain agreements or laws pertaining to the level of the minimum wage rate. Alternatively, it might be argued that the high and constant wage rate in the sector captures the various types of benefits offered to workers; these benefits include pecuniary rewards, stability, and job interest. We also assume that the wage rate in sector 3 is a fraction of that in the advanced sector, i.e., 


$$
w_{3}=\alpha w_{2}
$$

This is partly justified by the fact that the wage rate of part-time workers is fixed according to the standard of the economy in question. For example, the wage rate of part-time workers is approximately 800 yen per hour in Japan.

Thus, the labor allocation of unskilled labor is expressed as

or

$$
w_{1}=\left(w_{2} L_{2}+\alpha w_{2} L_{3}\right) /\left(L_{2}+L_{3}+L_{u}\right)
$$

$$
w_{1}\left(L_{2}+L_{3}+L_{u}\right)=w_{2}(1+\alpha \mu) L_{2},
$$

where

$$
\mu=L_{3} / L_{2}
$$

The exogenously given endowments impose the following resource constraints:

$$
\begin{gathered}
L_{1}+L_{2}+L_{3}+L_{u}=L+L^{*}, \\
H_{1}+H_{2}+H_{u}=H+H^{*},
\end{gathered}
$$

where $L, H$, and $K$ are the domestic endowments of unskilled labor, skilled labor, and capital, respectively, while $L^{*}$ and $H^{*}$ are the foreign inflows of unskilled labor and skilled labor, respectively. This completes the specification of our model with the fixed endowment of factors and the internationally determined prices. We have nine unknown variables $w_{1}, w_{3}, L_{1}, L_{2}, L_{3}, L_{u}, H_{1}, H_{2}$ and $H_{u}$, which are solved by nine equations (3)-(8), (10), and (11) for the given parameters, $s, w_{2}$, $\alpha, p_{1}, p_{2}, p_{3}, K_{1}, K_{2}, K_{3}, L, H, L^{*}$, and $H^{*}$.

\section{International Factor Movement and Unemployment}

\section{A. Immigration of unskilled labor}

In the present set-up of the model, with respect to the positive aspects of this analysis, the positive effects of the changes in factor endowment on the variables do not depend on whether the changes are autonomous increases or foreign inflows. The normative effects differ according to the reason for the changes. If the 
change is caused by the inflow of foreign factors, it additionally affects welfare through the change in the remittance. Therefore, the following results of unemployment apply to the case of an autonomous increase in the domestic endowment of unskilled labor.

First, we examine the effect of an inflow of unskilled foreign labor on the unemployment of unskilled and skilled labor. Comparative statics yield the following (see the Appendix):

$$
\left(d L_{u} / d L^{*}\right)=\left(p_{1}\right)^{2}\left(p_{2}\right)^{2} p_{3} F_{L L}^{3} C \Phi_{1} \Phi_{2} / \Delta>0
$$

where $\quad C=L_{2}+L_{3}+L_{u}, \Phi_{1}=\left\{F_{L L}^{1} F_{H H}^{1}-\left(F_{L H}^{1}\right)^{2}\right\}>0, \Phi_{2}=\left\{F_{L L}^{2} F_{H H}^{2}-\left(F_{L H}^{2}\right)^{2}\right\}>0$, and $\Delta$ is the value of the determinant of the coefficient matrix of the system, which can be shown to be negative (see the Appendix).

We obtain the effect of the inflow of foreign unskilled labor on the unemployment of skilled labor as follows:

$$
\left(d H_{u} / d L^{*}\right)=-w_{1} p_{1}\left(p_{2}\right)^{2} p_{3} F_{H L}^{1} F_{L L}^{3} \Phi_{2} / \Delta
$$

Thus, we have the following proposition.

Proposition 1. The increase in (foreign) unskilled labor increases the unemployment of unskilled labor, and it decreases the unemployment of skilled labor provided skilled and unskilled labor are technically complement each other in sector 1(i.e., $F_{H L}^{1}>0$ ).

The result is fairly straightforward and consistent with our economic intuition. The inflow of foreign unskilled workers increases the employment of unskilled labor in sector 1, while the employment in sectors 2 and 3 remains constant. A slight increase in employment is possible due to the decrease in the wage rate in sector 1 . However, the increase in employment in sector 1 is less than the inflow of foreign unskilled labor. As a result, the unemployment of unskilled labor eventually increases.

On the other hand, the induced increase in the employment of unskilled labor increases the marginal value product of skilled labor in sector 1. In turn, this increases the employment of skilled labor in sector 1 provided that skilled and unskilled labor are technically complement each other in the sector (i.e., $F_{L H}^{1}>0$ ), 
and then it decreases unemployment of skilled labor. Conversely, the employment of skilled labor decreases if skilled and unskilled labor are technically substitute each other (i.e., $F_{L H}^{1}<0$ ). This depends on the nature of the production technique employed in the industry. In the presence of three factors in the industry, both cases are possible. However, it may be more realistic to assume that skilled and unskilled labor are technically complement each other.

\section{B. Immigration of skilled labor}

Now consider the effect of the inflow of skilled labor on unemployment. Solving the system for $d L_{u}$ and $d H_{u}$ with respect to $d H^{*}$, we have

$$
d L_{u} / d H^{*}=0
$$

and

$$
d H_{u} / d H^{*}=1
$$

Our result can be summarized in the following proposition:

Proposition 2. The increase in (foreign) skilled labor increases the unemployment of skilled labor by exactly the same amount but does not affect the unemployment of unskilled labor.

Under the constant wage rate of skilled labor, the inflow of skilled labor is directly absorbed into the unemployment pool. Further, this inflow does not affect the market of unskilled labor. Thus, this policy cannot be employed to reduce both the types of unemployment.

\section{Production Subsidies and Unemployment}

\section{A. Subsidy to the traditional sector and unemployment}

We will now investigate the other policy tools that can be used to alleviate the problem of unemployment. Here, we consider the production subsidies provided to the sectors. This section examines the effect of the subsidy to the traditional sector 1. The effect of production subsidies can be captured by the increase in the prices under the assumption that the good prices are constant and the subsidies are initially zero. 
We obtain the effect of the subsidy to sector 1 as (see the Appendix)

$$
d L_{l} / d p_{1}=C p_{1} F_{L}^{1} F_{H H}^{1} p_{3} F_{L L}^{3}\left(p_{2}\right)^{2} \Phi_{2} / \Delta<0
$$

and

$$
d H_{u} / d p_{1}=-C p_{1} F_{L}^{1} F_{H L}^{1} p_{3} F_{L L}^{3}\left(p_{2}\right)^{2} \Phi_{2} / \Delta
$$

This leads to the following proposition.

Proposition 3. A production subsidy provided to sector 1 decreases the unemployment of unskilled labor, and it also decreases the unemployment of skilled labor provided that skilled and unskilled labor are technically complement each other in sector 1 (i.e., $F_{H L}^{1}>0$ ).

The production subsidy to the traditional sector 1 increases the value marginal product of unskilled labor of the sector. This directly increases the employment of unskilled labor in sector 1 . We can see that the subsidy does not change the employment of other two sectors. Thus, the subsidy decreases unemployment of unskilled labor. On the other hand, the expansion of sector 1 induces the increase the employment of skilled labor if skilled and unskilled labor are technically complement each other in sector 1 (i.e., $F_{H L}^{1}>0$ ). The subsidy will be used for training, education and job-search activities of unskilled labor.

\section{B. Subsidy to the advanced sector and unemployment}

Now let us examine the effect of the subsidy to the advanced sector 2 on unemployment. Comparative statics reveals that

and

$$
d L_{l} / d p_{2}=p_{3} F_{L L}^{3} \Pi\left(A p_{1} F_{H H}^{1}+C\left(p_{1}\right)^{2} \Phi_{1}\right) / \Delta<0
$$

$$
d H_{u} / d p_{2}=-p_{3} F_{L L}^{3}\left[\Lambda\left\{C\left(p_{1}\right)^{2} \Phi_{1}-w_{1} F_{H H}^{1}\right\}+w_{2} p_{1} F_{H L}^{1} \Pi\right] / \Delta,
$$

where $A=\left(w_{2}-w_{1}\right)<0, \Pi=p_{2}\left(F_{L}^{2} F_{H H}^{2}-F_{H}^{2} F_{L H}^{2}\right)<0$, and $\Lambda=p_{2}\left(F_{L}^{2} F_{H L}^{2}-F_{H}^{2} F_{L L}^{2}\right)>0$.

Thus, we obtain following proposition.

Proposition 4. A production subsidy provided to the advanced sector 
decreases the unemployment of unskilled labor, and it decreases the unemployment of skilled labor provided that

$$
\left[\Lambda\left\{C\left(p_{1}\right)^{2} \Phi_{1}-w_{1} F_{H H}^{1}\right\}+w_{2} p_{1} F_{H L}^{1} \Pi\right]<0 .
$$

The production subsidy provided to the advanced sector 2 expands the output, and then increases the employment of unskilled labor. Thus, this decreases unemployment of unskilled labor. Part of the increased employment in sector 2 comes from sector 1. This, in turn, decreases the employment of skilled labor in sector 1, while the expansion of sector 2 increases it if skilled and unskilled labor are technically complement each other in sector 1 (i.e., $F_{H L}^{1}>0$ ). Therefore, the total effect on skilled labor depends on the relative magnitude of these two offsetting effects. Proposition 3 provides the necessary and sufficient condition. The condition is a bit complicated. However, if the degree of technical complementality between skilled and unskilled labor in sector 2 is large and that in sector 1 is small, the induced increase in the employment of skilled labor in sector 2 will be relatively large compared with the decrease in the employment of skilled labor in sector 1 . This leads to the decrease in unemployment of skilled labor.

\section{Subsidy to sector 3 and unemployment}

Now, we will examine the production subsidy provided to sector 3 . This policy includes various subsidies provided for the support of small industries such as labor-absorbing, retailing, and food service industries. We can show that

$$
d L_{l} / d p_{3}=-\left(p_{2}\right)^{2} F_{L}^{3}\left\{w_{1} p_{1} F_{H H}^{1}-C\left(p_{1}\right)^{2} \Phi_{1}\right\} \Phi_{2} / \Delta<0
$$

and

$$
d H_{u} / d p_{3}=-\alpha w_{2} p_{1}\left(p_{2}\right)^{2} F_{L}^{3} F_{H L}^{1} \Phi_{2} / \Delta
$$

Thus, we arrive at the following proposition.

Proposition 5. A production subsidy provided to sector 3 decreases the unemployment of unskilled labor, and it increases the unemployment of skilled labor provided that skilled and unskilled labor are technically complement each other in sector 1 (i.e., $F_{H L}^{1}>0$ ).

The production subsidy provided to sector 3 increases the marginal value 
product of unskilled labor in the sector. In turn, this increases employment in sector 3 under the constant wage rate in the sector. The subsidy has no direct effect on two other sectors. Thus, the increase in the employment of sector 3 leads to the decrease in the unemployment of unskilled labor.

However, the increase in the employment of unskilled labor in sector 3 exerts an upward pressure on the expected wage income in the advanced area. This induces a labor movement from the traditional area to the advanced area, thus decreasing the employment of unskilled labor in the traditional sector. Therefore, the contraction of the traditional sector induces the decrease in the employment of skilled labor skilled and unskilled labor are technically complement each other in sector 1 (i.e., $F_{H L}^{1}>0$ ). This results in the increase in the unemployment of skilled labor since the subsidy does not affect the advanced sector.

Thus, this policy can reduce open unemployment of unskilled labor by increasing employment (or, in other words, disguised unemployment) in sector 3. However, it may decrease the employment of both skilled and unskilled labor in sector 1.

\section{Wage rate and Unemployment}

In this section, we investigate the exogenous change in the wage rate in sector 3. This change takes place, for example, when the part-time wage rate decreases due to recession, the buyers' market of unskilled labor, and so on. This can be captured by the change in $\alpha$. Thus, we have

$$
d L_{u} / d \alpha=-\left(p_{2}\right)^{2}\left\{\left(w_{2} L_{2} p_{3} F_{L L}^{3}+B\right) p_{1} F_{H H}^{1}+w_{2} C\left(p_{1}\right)^{2} \Phi_{1}\right\} \Phi_{2} / \Delta>0
$$

and

$$
d H_{u} / d \alpha=w_{2}\left(p_{2}\right)^{2}\left(L_{3} p_{3} F_{L L}^{3}+\alpha w_{2}\right) p_{1} F_{H L}^{1} \Phi_{2} / \Delta
$$

where $B=\left(\alpha w_{2}-w_{1}\right)<0$. Note that

$$
\left(L_{3} p_{3} F_{L L}^{3}+\alpha w_{2}\right)=-w_{3}(\xi-1)
$$

where $\xi=-L_{3} p_{3} F_{L L}^{3} / w_{3}$, that is, the elasticity of the wage rate in sector 3 with respect to its employment of unskilled labor. In this way, we obtain the following 
proposition.

Proposition 5. The decrease in the wage rate in sector 3 decreases the unemployment of unskilled labor, and it decreases unemployment of skilled labor provided that skilled and unskilled labor are technically complement each other in sector 1 (i.e., $F_{H L}^{1}>0$ ) and $\xi>1$.

The decrease in $w_{3}$ (or $\alpha$ ) directly increases the employment of unskilled labor in the sector 3. This, of course, contributes to reduce unemployment of unskilled labor. On the other hand, this increase in the employment in sector 3 may increase the expected wage income in the advanced area, $\left(w_{2} L_{2}+\alpha w_{2} L_{3}\right) /\left(L_{2}+L_{3}+L_{u}\right)$, and then induce unskilled labor into the area from the traditional area. This decreases the employment of unskilled labor in sector 1 . However, our result shows that the increase in the employment in sector 3 is larger than the possible decrease in the employment in sector 1 . Thus, the decrease in $w_{3}$ (or $\left.\alpha\right)$ reduces unemployment of unskilled labor even if it decreases the employment in sector 1 .

As to the effect on skilled labor, however, the change in the unskilled employment in sector 1 is of critical importance. Considering that $w_{2} d \alpha=p_{3} F_{L L}^{3} d L_{3}$ from (5) and (7), we have $\alpha w_{2}+L_{3} p_{3} F_{L L}^{3}=\alpha w_{2}\left\{1+\left(L_{3} / \alpha\right)\left(d \alpha / d L_{3}\right)\right\}$. Note that $\left\{1+\left(L_{3} / \alpha\right)\left(d \alpha / d L_{3}\right)\right\}<0$ is equivalent to that $d(1+\alpha \mu) / d \alpha>0$. In this case, therefore, the expected wage income in the advanced area decreases due to the decrease in $w_{3}$ (or $\alpha$ ). Thus, some of the unskilled daydreamer give up to stay in the advanced area and moves to the traditional area in order to secure the job. Then, if the direct increase in $L_{3}$ due to the decrease in $w_{3}$ (or $\alpha$ ) is sufficiently large, in the sense that $\left\{1+\left(L_{3} / \alpha\right)\left(d \alpha / d L_{3}\right)\right\}<0$, the unskilled employment in sector 1 increases. This in turn increases the skilled employment in the sector, and then reduces unemployment of skilled labor under the assumption that skilled and unskilled labor are technically complement each other in sector 1 and $\xi>1$.

\section{Concluding Remarks}

In this paper, we have focused on an economy that has two types of unemployment. The first type is the traditional unemployment that is caused by a relatively high and rigid common wage rate. This type of unemployment is often observed in elderly workers who obtain a relatively high wage rate as compared with their productivity. However, excessive expectations from a job may result in 
Table 1. The effects on unemployment

\begin{tabular}{lcc}
\hline & \multicolumn{2}{c}{ Unemployment } \\
& Unskilled labor & Skilled labor \\
\hline Inflow of unskilled labor $\left(L^{*}\right)$ & $\Uparrow$ & $(\Downarrow)$ \\
Inflow of skilled labor $\left(H^{*}\right)$ & Constant & $\Uparrow$ \\
Subsidy to sector 1 $\left(p_{1}\right)$ & $\Downarrow$ & $(\Downarrow)$ \\
Subsidy to sector $2\left(p_{3}\right)$ & $\Downarrow$ & $(\Downarrow)$ \\
Subsidy to sector 3 $\left(p_{3}\right.$ & $\Downarrow$ & $(\Uparrow)$ \\
Decrease in the wage rate in sector 3 $(\alpha)$ & $\Downarrow$ & $(\Downarrow)$ \\
\hline
\end{tabular}

*The symbols within parentheses imply that the results are conditional.

the unemployment of workers. This type of unemployment is observed among the younger generations. Both these types of unemployment result in social loss as well as individual hardships.

In this set-up, we have investigated the effects of international migration and other policies on the unemployment of both skilled and unskilled labor. The results are summarized in the table mentioned above. It can be seen that production subsidies and the decrease in the wage rate in sector 3 are effective in reducing the unemployment of unskilled labor. On the other hand, the inflow of foreign unskilled labor, production subsidies to sectors 1 and 2, and the decrease in the wage rate in sector 3 are effective in reducing the unemployment of skilled labor under certain conditions. The results obtained in this paper have important implications for alleviating the problem of unemployment. Thus, our results are useful to policy makers in order to consider the effective policies that are necessary to solve the problem of unemployment.

\section{Acknowledgements}

I wish to thank an anonymous referee for helpful comments and suggestions. I am extremely grateful to participants of the conference at University of New South Wales, Sydney, August 2006, the $8^{\text {th }}$ ETSG conference at Viena, and the seminar at Nagoya City University. I also greatly acknowledge the financial support received from the Japan Society for the Promotion of Science (Grant-in-Aid for Scientific Research, no. c-16530156 and c-19530210). 


\section{References}

Basu, K., 2000, Rural-urban Migration, Urban Unemployment and the Structural Transformation of a Dual Economy, Journal of International Trade and Economic Development 9, 137-149.

Batra, R. N. and N. Naqvi, 1987, Urban Unemployment and the Gains from Trade, Economica 54, 381-395.

Beladi, H. and N. Naqvi, 1988, Urban Unemployment and Non-Immiserizing Growth, Journal of Development Economics 28, 365-376.

Bhagwati, J. N. and T. N. Srinivasan, 1974, On Reanalysing the Harris-Todaro Model: Policy Rankings in the Case of Sector-Specific Sticky Wages, American Economic Review 64, 502-508.

Chao, C. C. and E. S. H. Yu, 1992, Imported Materials Prices, Urban Unemployment, and Welfare, International Review of Economics \& Finance 2, 121-32.

Chao, C. C. and E. S. H. Yu, 1996, International Capital Mobility, Urban Unemployment and Welfare, Southern Economic Journal 62, 486-92.

Chaudhuri, S., 2003, How and How Far to Liberalize a Developing Country with Informal Sector and Factor Market Distortions, Journal of International Trade and Economic Development 12, 375-398.

Corden, W. M. and R. Findlay, 1975, Urban Unemployment, Intersectoral Capital Mobility and Development Policy in a Dual Economy, Economica 42, 59-78.

$\mathrm{Gu}$, Wei and S. Yabuuchi, 2003, Local Content Requirements and Urban Unemployment, International Review of Economics and Finance 12, 481-494.

Gupta, M. R., 1993, Rural-urban Migration, Informal Sector and Development Policies, Journal of Development Economics 41, 137-151.

Harris, J. R. and M. Todaro, 1970, Migration, Unemployment and Development: A TwoSector Analysis, American Economic Review 60, 126-142.

Hazari, B. R. and P. M. Sgro, 1991, Urban-Rural Structural Adjustment, Urban Unemployment with Traded and Non-traded Goods, Journal of Development Economics $35,187-196$.

Khan, M. A., 1980, Dynamic Stability, Wage Subsidies and the Generalized HarrisTodaro Model, Pakistan Economic Review 19, 1-24.

Marjit, S., 1991, Agro-based Industry and Rural Urban Migration: A Case for an Urban Employment Subsidy, Journal of Development Economics 35, 393-398.

Marjit, S and H. Beladi, 2003, Possibility and Impossibility of Paradoxes in the Small Country Harris-Todaro Framework: A Unified Analysis, Journal of Development Economics 72, 379-385.

Neary, J. P., 1981, On the Harris-Todaro Model with Intersectoral Capital Mobility, Economica 48, 219-234.

Yabuuchi, S., 1993, Urban Unemployment, International Capital Mobility and Development Policy, Journal of Development Economics 41, 399-403. 
Yabuuchi, S., 1998, Urban Unemployment, Factor Accumulation, and Welfare, Review of Development Economics 2, 31-40.

Yabuuchi, S., 2007, Unemployment and International Factor Movement in the Presence of

Skilled and Unskilled Labor, Review of Development Economics 11, 437-449.

Yu E. S. H. and J. C. Jin, 2002, Technical Progress, Urban Unemployment, Outputs, and

Welfare under Variable Returns to Scale, International Review of Economics \& Finance 11, 411-25.

\section{Appendix}

Here we will show how to derive the mathematical expressions in the main text. Differentiating (3)-(8), (10), and (11), and arranging the terms, we obtain

$$
\left[\begin{array}{cccccccc}
-1 & p_{1} F_{L L}^{1} & 0 & 0 & 0 & p_{1} F_{L H}^{1} & 0 & 0 \\
0 & 0 & p_{2} F_{L L}^{2} & 0 & 0 & 0 & p_{2} F_{L H}^{2} & 0 \\
0 & 0 & 0 & p_{3} F_{L L}^{3} & 0 & 0 & 0 & 0 \\
-C & 0 & A & B & -w_{1} & 0 & 0 & 0 \\
0 & 1 & 1 & 1 & 1 & 0 & 0 & 0 \\
0 & 0 & 0 & 0 & 0 & 1 & 1 & 1 \\
0 & p_{1} F_{H L}^{1} & 0 & 0 & 0 & p_{1} F_{H H}^{1} & 0 & 0 \\
0 & 0 & p_{2} F_{H L}^{2} & 0 & 0 & 0 & p_{2} F_{H H}^{2} & 0
\end{array}\right]\left[\begin{array}{c}
d w_{1} \\
d L_{1} \\
d L_{2} \\
d L_{3} \\
d L_{u} \\
d H_{1} \\
d H_{2} \\
d H_{u}
\end{array}\right]=\left[\begin{array}{c}
-F_{L}^{1} d p_{1} \\
-F_{L}^{2} d p_{2} \\
w_{2} d \alpha-F_{L}^{3} d p_{3} \\
-w_{2} L_{3} d \alpha \\
d L^{*} \\
d H^{*} \\
0 \\
-F_{H}^{2} d p_{2}
\end{array}\right],
$$

where $A=\left(w_{2}-w_{1}\right)<0, B=\left(\alpha w_{2}-w_{1}\right)<0$ and $C=L_{2}+L_{3}+L_{u}$. Solving (A1) for $d L_{u}$ with respect to $d L^{*}$, we obtain (12) in the main text as follows.

$$
\left(d L_{u} / d L^{*}\right)=\left(p_{1}\right)^{2}\left(p_{2}\right)^{2} p_{3} F_{L L}^{3} C \Phi_{1} \Phi_{2} / \Delta>0
$$

where $\Phi_{1}=\left\{F_{L L}^{1} F_{H H}^{1}-\left(F_{L H}^{1}\right)^{2}\right\}>0, \Phi_{2}=\left\{F_{L L}^{2} F_{H H}^{2}-\left(F_{L H}^{2}\right)^{2}\right\}>0$, and

$$
\Delta=\left(p_{2}\right)^{2} p_{3} F_{L L}^{3}\left\{C\left(p_{1}\right)^{2} \Phi_{1}-w_{1} p_{1} F_{H H}^{1}\right\} \Phi_{2}<0
$$

Other results on comparative statics are obtained in a similar manner. 